\title{
EDITORIAL
}

\section{Monitoring nitric oxide: here to stay for bench and bedside}

\author{
P.E. Silkoff
}

$\mathbf{T}$ his editorial accompanies the publication, on April 15, 2005, of a joint American Thoracic Society (ATS) and European Respiratory Society (ERS) statement, which focuses on the measurement of exhaled and nasal nitric oxide (NO) [1]. This statement is an excellent example of collaboration between the two societies to produce a document of great relevance to researchers and clinicians alike. For the societies, the publication of recommendations in specific areas of practice is perhaps the best example of how these organisations lead to practical outcomes.

$\mathrm{NO}$ is an essential biological mediator of both physiological and pathological processes [2]. Its pivotal role in central and peripheral neurotransmission and smooth muscle relaxation is well established, while NO is also a mediator of inflammation and a player in oxidative stress pathways. Its net effect is probably a balance between its physiological and pathological roles, while, for our purposes, it serves as a marker for these processes.

Groups of researchers from many countries produced separate guidelines for the measurement of exhaled and nasal NO, which appeared in the European Respiratory Journal in 1997 [3], and the American Journal of Respiratory and Critical Care Medicine in 1999 [4]. The current document consolidates and builds upon these efforts. A separate ATS/ERS statement for NO measurement in children has been available since 2002 [5].

Those who access the statement in print [1] or at www.ersnet. org/no-guideline and www.thoracic.org/statements will be able to read background information about the following: $\mathrm{NO}$ measurement; online exhaled NO testing, where results are immediate; and offline exhaled NO measurement, where gas is collected for delayed measurement. Sections on paediatric exhaled NO measurement (a summary of the 2002 document [5]), nasal NO measurement, modelling of NO airway secretion, measurement in ventilated patients and recommended equipment specifications are also included. Two "recipes" to build offline NO collection devices are also accessible on the Internet.

Since the discovery that exhaled breath contains NO in 1991 [6], there has been sustained interest in the measurement of this marker as a noninvasive index of airway inflammation predominantly, but not exclusively, in asthma [7]. Nasal NO, released in the upper airway in relatively high concentrations

CORRESPONDENCE: P.E. Silkoff, 715 Bryn Mawr Avenue, Narbeth, PA 19072, USA. Fax: 1 3028858267. E-mail: philsilkoff@hotmail.com
[8], is mainly used for research, but shows great promise as a screening tool for primary ciliary dyskinesias, where levels are profoundly depressed [9].

The performance of any test requires standardisation so that results can be reproducible and comparable between laboratories. For lower respiratory tract $\mathrm{NO}$, the prevention of contamination by ambient $\mathrm{NO}$ and nasal $\mathrm{NO}$, both of which may be a higher concentration than that of the lower respiratory tract, and a tightly controlled exhalation flow rate, as levels vary about 35 -fold with flow rate [10], are essential for reproducible measures. Fortunately, single-breath exhalation against resistance facilitates velum closure, thus excluding nasal NO, but, at the same time, allowing flow rate to be tightly controlled. Online exhaled NO measurement is a simple, quick and noninvasive test that is easily performed by school-aged children and adults alike, while separate methods are applicable in very young children.

Many fads come and go, but, with $>1,000$ publications, this marker of airway inflammation has stood the test of time. Why all the excitement? Much of it has to do with the promising application of exhaled NO in asthma, a disease that has many phenotypic elements, such as airway calibre, bronchial responsiveness, inflammation and remodelling, which interact in complex ways to determine the severity and control of an individual's disease. Monitoring of lung function alone is increasingly appreciated to be insufficient to gain the most comprehensive assessment. Assessment of the inflammatory component using sputum eosinophils and adjustment of therapy accordingly has been shown to reduce asthma exacerbations [11]. The close link between exhaled NO and eosinophils suggests that exhaled NO could be used in place of sputum eosinophils [12], and the measurement of exhaled NO dose appears to predict asthma exacerbation in some preliminary reports [13-15]. Aside from predicting exacerbations, exhaled NO performs very well as a diagnostic test for asthma $[16,17]$, and may possibly be a way to predict the response to medication, e.g. inhaled corticosteroids [18]. Exhaled NO helps physicians to assess adherence, which is so poor for asthma therapy [19].

Recent advances have allowed testing in intubated patients [20], and are briefly described in the ATS/ERS statement. Understanding of the physiological determinants of $\mathrm{NO}$ secretion in the airway has led to a description of several flow-independent NO exchange parameters, namely the alveolar NO concentration, the bronchial wall NO concentration and the airway transfer factor for NO [21, 22]. Perturbation 
of these parameters differs between disorders that affect airways, e.g. asthma, and those that affect lung parenchyma, such as interstitial fibrosis [23]. These advances are briefly described and referenced in the updated statement.

For the application of NO to move from bench to bedside, there are several requirements. First, the value of exhaled NO must be established for specific disorders. Currently, asthma is the main disease that seems to justify NO measurement, but others may follow, e.g. monitoring of lung transplant patients. For asthma, while research has been extensive, we need to see well-powered and well-controlled studies that prove the impact of exhaled NO measurement on measures of asthma control in the widest sense, e.g. exacerbations, health-economic outcomes on quality of life and, in the longer term, on remodelling and prognosis. Importantly, as of yet, there are no published normal reference ranges for health and disease. Once more data are available, treatment guidelines need to address the noninvasive assessment of asthma. Medical devices need to pass the rigor of regulatory approval, and reimbursement codes are essential for widespread application to occur. Finally, technological advances must occur in NO measurement, which will result in inexpensive stable and simple devices that are applicable to the laboratory, but also to home measurement for more difficult patients, if exhaled NO proves to be useful in those patients.

This joint American Thoracic Society/European Respiratory Society statement should be a living, breathing document, through frequent updates. Researchers and clinicians are invited to send comments and suggestions about measurement issues to the contributors of the document, including this author, for discussion, if and when future revisions occur.

\section{REFERENCES}

1 Recommendations for standardized procedures for the online and offline measurement of exhaled lower respiratory nitric oxide and nasal nitric oxide in adults and children, 2005. Am J Respir Crit Care Med 2005; 171: 912-930.

2 Bruckdorfer R. The basics about nitric oxide. Mol Aspects Med 2005; 26: 3-31.

3 Kharitonov S, Alving K, Barnes PJ. Exhaled and nasal nitric oxide measurements: recommendations. The European Respiratory Society Task Force. Eur Respir J 1997; 10: 1683-1693.

4 Recommendations for standardized procedures for the online and off-line measurement of exhaled lower respiratory nitric oxide and nasal nitric oxide in adults and children1999. This official statement of the American Thoracic Society was adopted by the ATS Board of Directors, July 1999. Am J Respir Crit Care Med 1999; 160: 2104-2117.

5 Baraldi E, de Jongste JC. Measurement of exhaled nitric oxide in children, 2001. Eur Respir J 2002; 20: 223-237.

6 Gustafsson LE, Leone AM, Persson MG, Wiklund NP, Moncada S. Endogenous nitric oxide is present in the exhaled air of rabbits, guinea pigs and humans. Biochem Biophys Res Commun 1991; 181: 852-857.

7 Barnes PJ, Liew FY. Nitric oxide and asthmatic inflammation. Immunol Today 1995; 16: 128-130.
8 Lundberg JO, Palm J, Alving K. Nitric oxide but not carbon monoxide is continuously released in the human nasal airways. Eur Respir J 2002; 20: 100-103.

9 Karadag B, James AJ, Gultekin E, Wilson NM, Bush A. Nasal and lower airway level of nitric oxide in children with primary ciliary dyskinesia. Eur Respir J 1999; 13: 1402-1405.

10 Silkoff PE, McClean PA, Slutsky AS, et al. Marked flowdependence of exhaled nitric oxide using a new technique to exclude nasal nitric oxide. Am J Respir Crit Care Med 1997; 155: 260-267.

11 Green RH, Brightling CE, McKenna S, et al. Asthma exacerbations and sputum eosinophil counts: a randomised controlled trial. Lancet 2002; 360: 1715-1721.

12 Jatakanon A, Lim S, Kharitonov SA, Chung KF, Barnes PJ. Correlation between exhaled nitric oxide, sputum eosinophils, and methacholine responsiveness in patients with mild asthma. Thorax 1998; 53: 91-95.

13 Harkins MS, Fiato KL, Iwamoto GK. Exhaled nitric oxide predicts asthma exacerbation. J Asthma 2004; 41: 471-476.

14 Jones SL, Kittelson J, Cowan JO, et al. The predictive value of exhaled nitric oxide measurements in assessing changes in asthma control. Am J Respir Crit Care Med 2001; 164: 738-743.

15 Pijnenburg MW, Hofhuis W, Hop WC, De Jongste JC. Exhaled nitric oxide predicts asthma relapse in children with clinical asthma remission. Thorax 2005; 60: 215-218.

16 Deykin A, Massaro AF, Drazen JM, et al. Exhaled nitric oxide as a diagnostic test for asthma: online versus offline techniques and effect of flow rate. Am J Respir Crit Care Med 2002; 165: 1597-1601.

17 Smith AD, Cowan JO, Filsell S, et al. Diagnosing asthma: comparisons between exhaled nitric oxide measurements and conventional tests. Am J Respir Crit Care Med 2004; 169: 473-478.

18 Szefler SJ, Phillips BR, Martinez FD, et al. Characterization of within-subject responses to fluticasone and montelukast in childhood asthma. J Allergy Clin Immunol 2005; 115: 233-242.

19 Beck-Ripp J, Griese M, Arenz S, Koring C, Pasqualoni B, Bufler P. Changes of exhaled nitric oxide during steroid treatment of childhood asthma. Eur Respir J 2002; 19: 1015-1019.

20 Tornberg DC, Bjorne H, Lundberg JO, Weitzberg E. Multiple single-breath measurements of nitric oxide in the intubated patient. Am J Respir Crit Care Med 2003; 168: 1210-1215.

21 Silkoff PE, Sylvester JT, Zamel N, Permutt S. Airway nitric oxide diffusion in asthma: role in pulmonary function and bronchial responsiveness. Am J Respir Crit Care Med 2000; 161: 1218-1228.

22 Tsoukias NM, George SC. A two-compartment model of pulmonary nitric oxide exchange dynamics. J Appl Physiol 1998; 85: 653-666.

23 Lehtimaki L, Kankaanranta $\mathrm{H}$, Saarelainen $\mathrm{S}$, et al. Extended exhaled NO measurement differentiates between alveolar and bronchial inflammation. Am J Respir Crit Care Med 2001; 163: 1557-1561. 